\title{
COMPLICAÇÕES BILIARES DO TRANSPLANTE HEPÁTICO COM O EMPREGO OU NÃO DO TUBO EM T
}

\author{
BILIARY COMPLICATIONS IN LIVER TRANSPLANTATION RELATED OR NOT \\ TO THE USE OF T-TUBE
}

\author{
Luiz Sérgio Leonardi, TCBC-SP ${ }^{1}$ \\ Ilka de Fátima Santana Ferreira Boin, ACBC-SP2 \\ Francisco Callejas Neto, TCBC-SP ${ }^{3}$ \\ Cléber Soares Júnior ${ }^{4}$
}

\begin{abstract}
RESUMO: O aperfeiçoamento da técnica operatória do transplante hepático reduziu o número de complicações biliares, mas os índices de morbidade e mortalidade relacionadas a estas complicações ainda preocupam os cirurgiões. Assim, é importante avaliar novas opções terapêuticas relativamente aos procedimentos operatórios convencionais. De setembro de 1991 a setembro de 1998, foram analisadas as complicações biliares observadas em 78 pacientes submetidos ao transplante hepático; anastomose coledococoledociana com emprego do tubo em T (CCT) foi praticada em 16 pacientes ou 20,5\%, anastomose coledococoledociana sem a utilização do tubo em T (CC) em 50 ou $64,1 \%$ e anastomose coledocojejunal (CJ) em 12 ou 15,4\%. Foram observadas $24(31,2 \%)$ complicações biliares sendo 12 durante o $1^{\mathrm{o}}$ mês e as demais no pós-operatório tardio. Ocorreram 12/78 (15,6\%) fístulas $(\mathrm{CCT}=5, \mathrm{CC}=$ $6, \mathrm{CJ}=1), 9 / 78(11,7 \%)$ estenose $(\mathrm{CCT}=1, \mathrm{CC}=8)$ e $3 / 78$ calculose $(\mathrm{CCT}=1, \mathrm{CC}=2)$. A colangiopancreatografia retrógrada endoscópica (CPRE) realizada em 19/78 pacientes ou 24,7\% ofereceu resultados satisfatórios em 13 $(61,9 \%)$. O tratamento endoscópico foi praticado em 11 casos de fístula biliar oferecendo bons resultados em quatro do grupo CCT e 5/6 do grupo CC; por outro lado, nos oito casos de estenose da anastomose (grupo CC) o tratamento endoscópico mostrou-se eficiente em $4 / 8$ pacientes. Complicações biliares ocorreram em 7/16 casos ou 43,75\% (grupo CCT) e 16/50 ou 32\% do grupo CC, somente nove entre as 24 complicações biliares necessitaram de reoperações $(\mathrm{CCT}=1, \mathrm{CC}=8)$. Além destas, entre os 78 , ocorreu trombose da artéria hepática (T.A.H.). Nesta casuística ocorreram 8/78 (10,4\%) óbitos (5 T.A.H., 1 CCT e 2 CC). O tempo de seguimento médio pós-tratamento das complicações biliares foi de 14 meses variando de um a 6,8 anos. A incidência global das complicações biliares observadas nesta série consecutiva de 78 pacientes foi maior nos grupos CCT (7/16) CC (16/50) quando comparadas ao grupo CJ. Não houve diferenças significativa quanto à ocorrência de fístula e estenoses nos grupos CCT e CC, quando comparadas. A incidência de complicações biliares precoces e tardias foi semelhante em ambos os grupos CCT e CC. Estes resultados sugerem que a incidência de fístulas e estenoses biliares, não é significativamente pelo emprego do tubo em T. O tratamento endoscópico indicado em casos selecionados permite diagnóstico acurado apresentando-se como tratamento de primeira escolha frente a estas complicações.
\end{abstract}

Unitermos: Transplante hepático; Complicações biliares; Colangiografia

\section{INTRODUÇÃO}

Mesmo com o aperfeiçoamento da técnica operatória na reconstrução da via biliar do transplante hepático ortotópico, o número de complicações, embora venha decrescendo, constitui ainda preocupação pela mortalidade e morbidade que provoca ${ }^{1,2}$.
As complicações biliares mais freqüentemente observadas são as fístulas e as estenoses. As fístulas biliares são referidas de $5 \%$ a $33 \% \%^{2,3,4}$, enquanto que as estenoses ocorrem em até $10 \%$ dos casos 5 .

As técnicas de reconstrução mais freqüentemente utilizadas são a anastomose coledococoledociana, com ou sem o emprego do dreno em T, e a anastomose coledoco-

1. Professor Titular da Disciplina de Moléstias do Aparelho Digestivo do Departamento de Cirurgia da FCM-UNICAMP

2. Professora Assistente da Disciplina de Moléstias do Aparelho Digestivo do Departamento de Cirurgia da FCM-UNICAMP

3. Professor Assistente e Endoscopista da Disciplina de Moléstias do Aparelho Digestivo do Departamento de Cirurgia da FCM-UNICAMP

4. Residente de Cirurgia da Disciplina de Moléstias do Aparelho Digestivo Departamento de Cirurgia da FCM-UNICAMP

Recebido em 20/8/99

Aceito para publicação em 29/5/2000

Trabalho realizado na Disciplina de Moléstias do Aparelho Digestivo do Departamento Cirurgia da Faculdade de Ciências Médicas da Universidade de Campinas - FCM-UNICAMP 
jejunal com o emprego de alça exclusa em Y de Roux. Embora o emprego do tubo em T na anastomose coledococoledociana tenha merecido a preferência da maioria dos autores $^{6}$ ainda persistem dúvidas quanto à escolha da técnica com o menor número de complicações. Assim, na presente série avaliou-se retrospectivamente as complicações pósoperatórias diretamente relacionadas às três técnicas de reconstrução biliar empregadas, representadas principalmente por fístulas e estenoses. Este trabalho tem também como objetivo avaliar retrospectivamente a incidência de complicações biliares observadas com o emprego ou não do tubo em T nos pacientes submetidos a transplante hepático. Avaliou-se também o tratamento endoscópico utilizado como primeira opção frente às complicações biliares pós-operatórias.

\section{PACIENTES E MÉTODOS}

No período de setembro de 1991 a setembro de 1998 foram realizados 78 transplantes hepáticos e quatro retransplantes no Hospital de Clínicas da UNICAMP. A idade dos 72 pacientes adultos variou de 15 a 58 anos (média de 36,2 anos), enquanto que nas seis crianças a idade variou de nove a 14 anos (média de 11,8 anos); quanto à raça, $75(96,1 \%)$ eram brancos e três $(3,9 \%)$ negros. Nesta série 55 pacientes correspondiam ao sexo masculino $(70,5 \%)$ e 23 ao feminino $(29,5 \%)$.

As causas das hepatopatias crônicas responsáveis pela indicação do transplante estão relacionadas na Tabela 1 . Em cinco $(6,4 \%)$ pacientes a indicação foi conseqüente à insuficiência hepática fulminante.

Para efeito de avaliação dos resultados, os doentes foram subdivididos em três grupos de acordo com a técnica de reconstrução da via biliar empregada:

- Grupo CCT - anastomose coledococoledociana com emprego do dreno em $\mathrm{T}$.

- Grupo CC - anastomose coledococoledociana sem o emprego do dreno em $\mathrm{T}$.

- Grupo CJ - anastomose coledocojejunal.

As complicações foram classificadas em imediatas (até $30^{\circ}$ dia de pós-operatório) e tardias. As complicações biliares observadas foram fístulas, estenoses, necrose e calculose.

A análise estatística foi realizada segundo o teste do Qui² com corrreção de Yates quando necessário.

A técnica operatória standard ${ }^{7}$ sem o emprego de circulação assistida venovenosa foi empregada em 14 transplantes $(17,9 \%)$ e em um retransplante $(1,3 \%)$, enquanto a técnica de piggyback (conservação da veia cava) foi realizada em 64 transplantes $(82,1 \%)$ e em três retransplantes $(3,9 \%)$, conforme técnica anteriormente descrita $^{8}$. A duração das operações variou de 4.3 até 13 horas (média de 8,7 horas), enquanto o tempo de isquemia quente (TIQ), teve média de 70 minutos e o tempo de isquemia fria (TIF) média de 11,19 horas. Em todos os pacientes foi utilizada a solução de preservação da Universidade de Wisconsin para a conservação do órgão. $\mathrm{O}$
Tabela 1

Distribuição dos casos conforme as doenças responsáveis pela indicação do transplante hepático

\begin{tabular}{l|c|c}
\hline Indicação & $\begin{array}{c}N^{o} d e \\
\text { casos }\end{array}$ & $\%$ \\
\hline Hepatite Crônica por vírus C & 33 & 42,2 \\
Alcoolismo & 12 & 15,4 \\
Cirrose Biliar Primária & 5 & 6,4 \\
Insuficiência Hepática Fulminante & 5 & 6,4 \\
Colangite Esclerosante Primária & 4 & 5,1 \\
Deficiência de a 1 antitripsina & 4 & 5,1 \\
Criptogenética & 3 & 3,8 \\
Hepatite Crônica por vírus B & 2 & 2,6 \\
Hepatite Auto-imune & 2 & 2,6 \\
Hepatite por vírus C e Hepatoma & 2 & 2,6 \\
Hepatite por vírus B e Hepatoma & 2 & 2,6 \\
Síndrome de Budd-Chiari & 1 & 1,3 \\
Paramiloidose Familiar & 1 & 1,3 \\
Hepatite por vírus C e Alcoolismo & 1 & 1,3 \\
Alcoolismo e Hepatoma & 1 & 1,3 \\
\hline Total & 78 & 100 \\
\hline
\end{tabular}

esquema tríplice de imunossupressão, utilizado em todos os pacientes, foi ciclosporina, azatioprina e corticóide.

No tocante à reconstrução biliar, até o 23o caso operado praticou-se anastomose coledococoledociana término-terminal com emprego de tubo em T de borracha ${ }^{9}$, exteriorizado por contra-abertura no colédoco do receptor em 16 pacientes $(20,8 \%)$. Esta técnica CCT foi praticada nos casos em que as bocas anastomóticas apresentavamse com diâmetros equivalentes. Utilizou-se fio monofilamentar absorvível de polidioxanona de $\mathrm{n}-6$ zeros. A sutura da parede posterior foi realizada preferencialmente com chuleio simples e a da parede anterior com pontos separados. As anastomoses foram praticadas de modo a cooptar as extremidades do colédoco do receptor e do doador tomando-se o cuidado de se assegurar a permeabilidade a montante do colédoco do doador e a jusante do colédoco do receptor com sonda de plástico de no 6 ou 8. Nesta técnica CCT, após o término da anastomose, realizou-se colangiografia intra-operatória com contraste iodado diluído a $50 \%$.

Utilizou-se a anastomose coledococoledociana CC sem o emprego do tubo em $\mathrm{T}$ em 50 pacientes $(63,6 \%)$, utilizando-se os mesmos passos da técnica anteriormente descrita.

Praticou-se a técnica da anastomose coledocojejunal CJ em 12 pacientes (15,6\%). Esta técnica foi indicada quando havia desproporção das bocas anastomóticas, doença do colédoco do receptor ou friabilidade de uma das extremidades. A anastomose foi sempre terminolateral com pontos separados de fio monofilamentar absorvível de polidioxanona de $\mathrm{n}^{\mathrm{o}} 4$ zeros. 
Com relação aos retransplantes praticou-se a reconstrução biliar com anastomose coledococoledociana sem o emprego do dreno em $\mathrm{T}$ em três pacientes $(3,9 \%)$ nos quais havia sido praticada esta mesma anastomose na primeira cirurgia; e coledocojejunal em um paciente $(1,3 \%)$ no qual havia sido praticada anastomose coledococoledociana com tubo em $\mathrm{T}$ na primeira cirurgia.

Todos os pacientes foram submetidos a controle de exames laboratoriais e radiológicos no pós-operatório conforme o protocolo desta Unidade. Assim, especificamente para o estudo das vias biliares foram solicitados exames bioquímicos para avaliar-se as funções hepáticas, tanto canalicular como hepatocítica. Também no pósoperatório imediato foi realizada ultra-sonografia abdominal, na primeira semana e posteriormente sempre que necessário.

Os pacientes portadores de tubo em $\mathrm{T}$ foram submetidos à colangiografia através do mesmo no $10^{\circ}$ dia de pós-operatório; o dreno foi então fechado, caso o exame não revelasse extravasamento ou dificuldade de progressão do contraste (caso contrário o dreno permaneceria aberto e repetir-se-ia o exame no decorrer da evolução do paciente). Os drenos em $\mathrm{T}$ foram retirados em média de quatro a seis meses após o transplante. A colangiopancreatografia retrógrada endoscópica (CPRE) foi realizada como complemento da colangiografia (através do dreno em T) nos casos de dúvidas quanto ao diagnóstico, e como procedimento de primeira linha nos casos de coledocoanastomose sem o emprego do dreno em T. Durante a evolução clínica, tanto no pós-operatório imediato como tardio, quando houve aumento das enzimas, notadamente as canaliculares, realizou-se ultra-sonografia abdominal e caso houvesse dilatação das vias biliares ou coleção abdominal sugerindo obstrução biliar ou fístula, procedeu-se a colangiopancreatografia retrógrada endoscópica (CPRE). Alguns pacientes foram submetidos ao exame cintilográfico das vias biliares no pós-operatório quando necessário. Em se tratando de portadores de anastomose coledocojejunal este exame foi indicado com exclusividade, sempre que necessário.

\section{RESULTADOS}

No grupo CCT com 16 pacientes, ocorreram quatro $(25 \%)$ casos de fístula biliar precoce (Tabela 2). O diagnóstico foi estabelecido através de colangiografia pelo tubo em $\mathrm{T}$ realizada em torno do $10^{\circ}$ dia de pós-operatório que revelou extravasamento de contraste pelo local da emergência do tubo em T no colédoco do receptor (Figura 1). $\mathrm{O}$ tratamento destes pacientes consistiu em esfincterotomia endoscópica em dois $(12,5 \%)$ e esfincterotomia associada à colocação de prótese endoscópica em um $(6,25 \%)$; em outro $(6,25 \%)$ a conduta foi expectante. O paciente submetido à colocação de prótese endoscópica evoluiu com infecção peritoneal e sepse ocorrendo o óbito no 4º mês de pós-operatório. Nos outros três $(18,75 \%)$ casos houve evolução clínica satisfatória com diminuição do débito e fechamento da fístula em média até a oitava semana de pósoperatório. Ainda neste grupo ocorreu um caso de fístula tardia ao nível da anastomose $(6,25 \%)$ diagnosticada pela colangiografia através do tubo em T (Tabela 2); este diagnóstico foi confirmado pela colangiografia retrógrada endoscópica no 39 dia de pós-operatório. Este paciente permaneceu assintomático pelo período de dois anos após o que apresentou estenose tardia ao nível da anastomose coledociana e presença de cálculos. O paciente foi então submetido à anastomose biliodigestiva coledocoduodenal laterolateral com a retirada dos cálculos coledocianos. No momento o paciente se encontra no $2^{2}$ mês de pós-operatório e assintomático.

No grupo CC, com 50 pacientes ocorreram seis casos $(12 \%)$ de fístula biliar (Tabela 2). Em cinco (10\%) destes casos a fístula foi diagnosticada precocemente (até o 30 dia de pós-operatório), havendo apenas um caso de fístula tardia (2\%). O diagnóstico precoce das fístulas foi feito através de CPRE em quatro $(8 \%)$ pacientes nos quais houve extravasamento de contraste ao nível da anastomose; em outro paciente com fístula precoce o diagnóstico deu-se à saída de bile pelo dreno tubular abdominal em grande quantidade no $2 \underline{0}$ dia de pós-operatório. Procedeuse à relaparotomia sendo identificada fístula ao nível da anastomose e realizada a anastomose biliodigestiva cole-

Tabela 2

Distribuição do número de casos de complicações biliares de acordo com o tipo de reconstrução biliar e período de acometimento após a realização do transplante de fígado

\begin{tabular}{l|c|c|c|c|c|c}
\hline Anastomose & \multicolumn{2}{|c|}{ CCT } & \multicolumn{2}{c}{ CC } & \multicolumn{2}{c}{ Tardio } \\
\hline Período & Precoce & Tardio & Precoce & Tardio & Precoce \\
Fístula & 4 & 1 & 5 & 1 & 0 \\
Estenose & 0 & 1 & 0 & 8 & 0 & 0 \\
Calculose & 0 & 1 & 0 & 2 & 0 & 0 \\
\hline Total & $25 \%$ & $18,75 \%$ & $10 \%$ & $22 \%$ & $0 \%$ \\
& $(4 / 16)$ & $(3 / 16)$ & $(5 / 50)$ & $(11 / 50)$ & $(0)$ & $(1 / 12)$ \\
\hline
\end{tabular}

$C C T=$ Anastomose coledococoledociana com o uso do tubo em $T$ (16 casos)

$C C=$ Anastomose coledococoledociana sem uso do tubo em $T$ (50 casos)

CJ = Anastomose coledocojejunal (12 casos) 


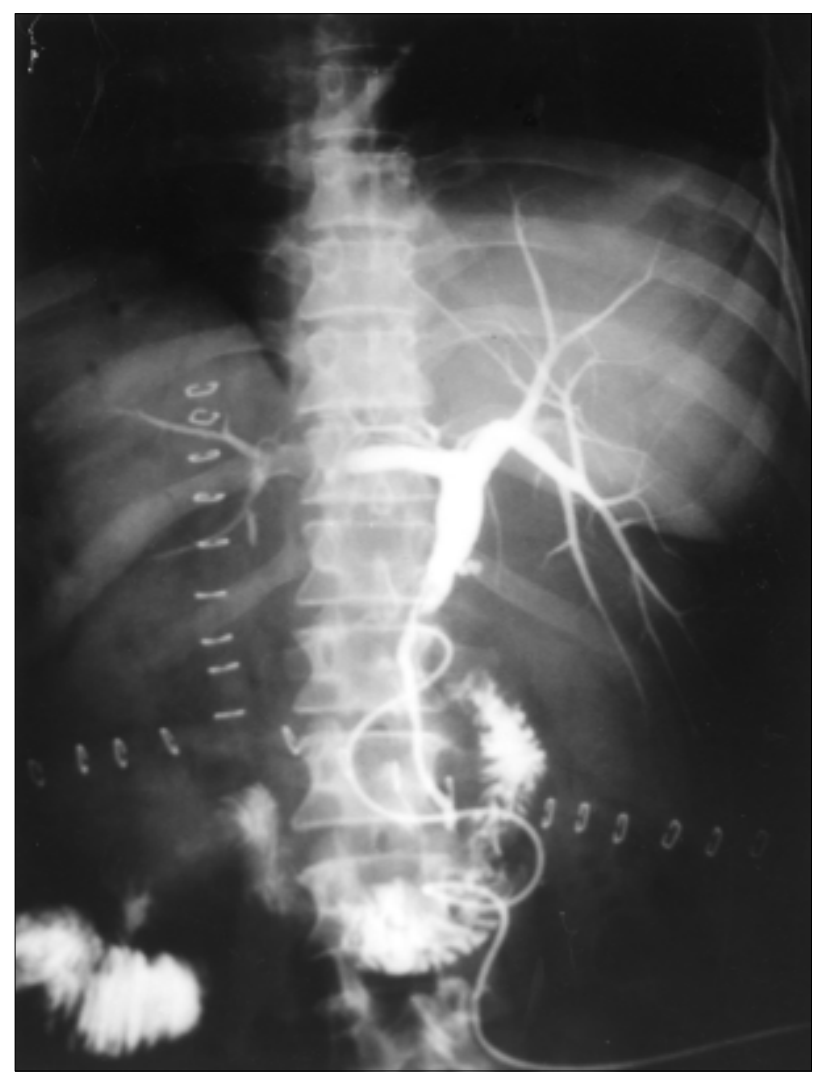

Figura 1 - Colangiografia através do tubo em T mostrando fístula pelo orifício de inserção do dreno.

docojejunal em Y de Roux, ocorrendo óbito no pós-operatório imediato por insuficiência respiratória. Dois pacientes (4\%) submetidos à CPRE foram tratados com conduta expectante com boa evolução clínica imediata; tardiamente, um destes desenvolveu estenose da via biliar associada à calculose, Figura 2, e foi submetido após um ano à anastomose biliodigestiva coledocojejunal em Y de Roux com retirada dos cálculos coledocianos. Em dois pacientes realizou-se a esfincterotomia endoscópica mais colocação de prótese; em um destes ocorreu ascite biliar necessitando tratamento cirúrgico para lavagem e drenagem da cavidade abdominal. $\mathrm{O}$ outro paciente apresentou calculose biliar intra-hepática associada à estenose coledociana tardia; que será adiante referido.

Ocorreu apenas um caso (2\%) de fístula biliar tardia no grupo $\mathrm{CC}$ em paciente portador de cirrose hepática por vírus $\mathrm{B}$ e hepatoma. $\mathrm{O}$ diagnóstico foi confirmado e tratado endoscopicamente, com colocação de prótese na via biliar e laparotomia exploradora para drenagem do coleperitônio.

Nos pacientes do grupo $\mathrm{CC}$ ocorreram oito casos (16\%) de estenose biliar, Tabela 2, todas tardias. O diagnóstico foi confirmado através de CPRE (30 dias a sete meses após o transplante) mostrando obstrução ao nível da anastomose em todos os pacientes.

O tratamento consistiu em esfincterotomia endoscópica sem colocação de prótese em um paciente (2\%), e

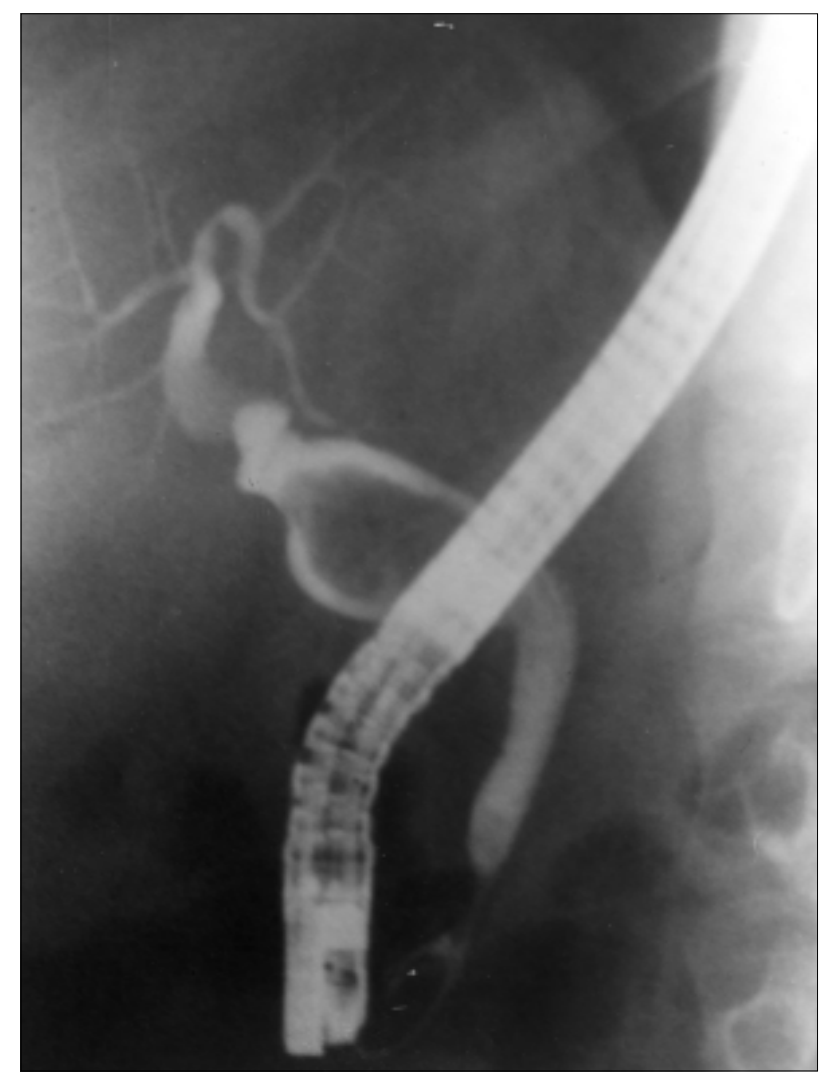

Figura 2 - Colangiopancreatografia retrógrada endoscópica mostrando estenose ao nível da anastomose e calculose. Paciente submetido à reconstrução biliar sem o emprego do tubo em $T$.

com colocação de prótese em cinco pacientes (10\%), sendo que em um destes $(2 \%)$ houve necessidade de tratamento cirúrgico subseqüente em virtude da prótese não drenar satisfatoriamente, praticando-se anastomose coledocojejunal terminolateral em Y de Roux; em outros dois (4\%) foi realizada anastomose coledocojejunal em Y de Roux como primeira opção em virtude do insucesso do tratamento endoscópico.

Ocorreu calculose da via biliar em três pacientes, um do grupo CCT, dois do grupo CC. Todos foram submetidos à CPRE sem êxito na retirada dos cálculos. Os pacientes foram submetidos à anastomose biliodigestiva coledocojejunal, e o pertencente ao grupo CCT foi submetido à anastomose coledocoduodenal. Houve óbito em um paciente do grupo CC. Neste paciente observou-se, na cirurgia, calculose biliar e estenose coledociana associada à erosão da veia porta; submetido à anastomose coledocojejunal, o paciente veio a falecer no 3 o dia de pós-operatório por insuficiência hepática aguda grave secundária à trombose de veia porta.

Na presente série de 78 pacientes a trombose da artéria hepática ocorreu em cinco transplantes $(6,5 \%)$ (Tabela 3). Em um paciente ocorreu no 2o dia de pósoperatório; praticado o retransplante o paciente evoluiu para o óbito. Em outro caso a trombose arterial ocorreu no 15 dia de pós-operatório; foi então realizada a ex- 
Tabela 3

Distribuição do número de casos de trombose arterial segundo o tipo de anastomose biliar e sua evolução

\begin{tabular}{c|l}
\hline Anastomose biliar & \multicolumn{1}{c}{ Evolução } \\
\hline CCT & Retransplante/Óbito \\
CC & Retransplante/Óbito \\
CC & Necrose de via biliar/Óbito \\
CC & Necrose de via biliar/Óbito \\
CJ & Reoperação/fístula/Óbito
\end{tabular}

$C C T=$ anastomose coledococoledociana com tubo em $T$ $C C=$ anastomose coledococoledociana sem tubo em $T$ $C J=$ anastomose coledocojejunal

ploração cirúrgica da artéria hepática havendo necessidade de se desfazer a anastomose coledocojejunal, tendo esta paciente do grupo CJ apresentado fístula biliar conseqüente à necrose do colédoco do doador, ocorrendo óbito um ano após, por sepse e insuficiência de múltiplos órgãos e sistemas. Em outro paciente praticou-se o retransplante sem sucesso após o tratamento com prótese biliar para estenose.

Outros dois pacientes $(3,9 \%)$ apresentaram necrose extensa da via biliar (Figura 3), ocorrendo óbito por insuficiência de múltiplos órgãos e sistemas (IMOS) em torno do $2^{\mathrm{o}}$ ao $4^{\mathrm{o}}$ mês de pós-operatório (todos pacientes eram do grupo CC).

Dilatação do ducto biliar relativa ao colédoco do receptor (disfunção papilar) ocorreu em um paciente $(1,3 \%)$ pertencente ao grupo CCT. Tratava-se de paciente alcoólista no qual não se demonstrou estenose orgânica. Submetido à esfincterotomia endoscópica apresentou boa evolução clínica.

Entre as complicações biliares observadas nos 78 pacientes (Tabela 2 ) foram praticadas nove $(11,7 \%$ ) reoperações sendo seis conseqüentes à fístula e três à estenose biliar. Assim, nos portadores de fístula biliar foram realizadas as seguintes reoperações: anastomose coledocoduodenal em um caso no grupo CCT; anastomose coledocojejunal em três e laparotomia para drenagem de coleperitônio em dois no grupo CC; apenas em um caso deste grupo realizou-se anastomose coledocojejunal precoce.

Os portadores de estenose biliar tardia, todos do grupo $\mathrm{CC}$, foram submetidos a três anastomoses coledocojejunais.

$\mathrm{Na}$ presente série ocorreram oito óbitos $(10,4 \%)$, sendo um no grupo CCT e dois no grupo CC, dos quais um precoce. Os outros cinco óbitos foram secundários à trombose da artéria hepática.

Quanto ao tratamento endoscópico mediante a esfincterotomia associada ou não ao emprego de prótese coledociana foi utilizado em 19 pacientes observando-se resultados satisfatórios em $13(61,9 \%)$.

Destes, no grupo CCT, foi eficiente no tratamento de três fístulas precoces e uma tardia posteriormente reoperada.

Quanto ao grupo CC apresentou bons resultados imediatos em cinco casos de fístula e seis de estenose tardia, dos quais, depois, um reoperado.

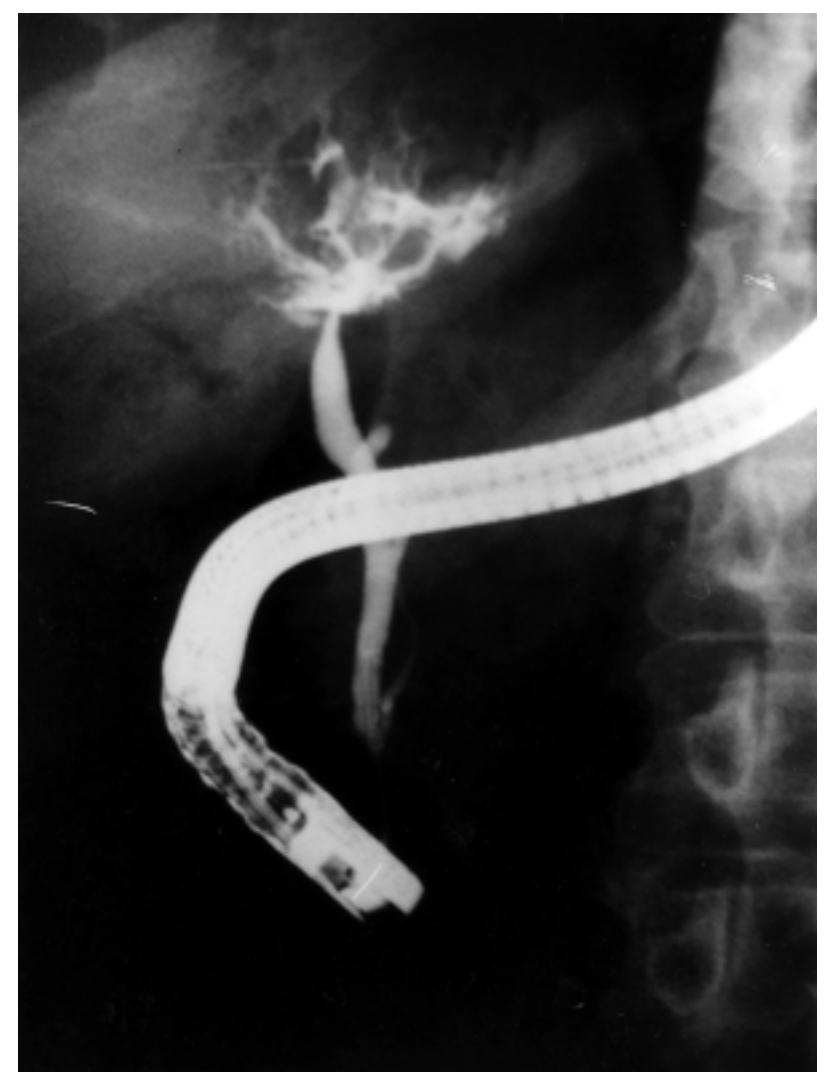

Figura 3 - Colangiopancreatografia retrógrada endoscópica mostrando necrose da via biliar em paciente com trombose arterial.

O tempo médio de seguimento após as complicações biliares foi de 14 meses (1-6,8\%)

Não houve diferença estatisticamente significante com relação ao número de complicações, número de reoperações e mortalidade quando comparadas às anastomose coledococoledocianas com e sem o emprego do tubo em $\mathrm{T}$ e as anastomose coledocojejunais, segundo o teste do Qui² (significância: $\mathrm{p}<0,05$ ).

\section{DISCUSSÃO}

Na presente série de 78 transplantes hepáticos ortotópicos, inicialmente realizou-se a reconstrução biliar praticando-se a anastomose coledococoledociana com o emprego do tubo em $\mathrm{T}$ e a anastomose coledocojejunal. Avaliando-se os resultados observados, optou-se pela realização da anastomose coledococoledociana sem a utilização do tubo em $\mathrm{T}^{10}$ atendendo ao princípio geral de tornar o ato operatório mais rápido e simples. A anastomose coledococoledociana foi praticada utilizando-se fio de polidioxanona $\mathrm{n}^{\mathrm{o}} 6$ zero absorvível. Recentemente foi demonstrado que este tipo de fio monofilamentar absorvível apresenta menor índice de complicações biliares comparativamente a outros por apresentar reação inflamatória menos intensa ${ }^{11}$.

Quanto ao tipo de sutura empregado ainda não há unanimidade entre os autores se a mesma deva ser contí- 
nua ou com pontos separados ${ }^{6}$. Nesta série sistematicamente se praticou sutura contínua na parede posterior e com pontos separados na anterior.

A anastomose coledococoledociana com a utilização do tubo em T é ainda hoje método preferido pela maioria dos cirurgiões ${ }^{6}$ pois preserva o esfíncter de ODDI, reduz as possibilidades do refluxo entérico na árvore biliar, permite o estudo radiológico no pós-operatório, bem como o monitoramento da bile produzida. Outros autores consideram que a incidência de complicações é semelhante entre as anastomoses coledococoledocianas com e sem o emprego do tubo em $\mathrm{T}^{12}$.

$\mathrm{Na}$ presente série, no grupo CCT, entre os 16 pacientes, o estudo radiográfico no pós-operatório imediato através do dreno em T permitiu o diagnóstico de fístula biliar precoce, ao nível da inserção do tubo em T no colédoco do receptor em quatro casos $(25 \%)$, e fístula tardia no local da anastomose em um caso $(6,25 \%)$. Nos quatro casos de fístula biliar pelo orifício de inserção do dreno em $\mathrm{T}$ os procedimentos endoscópicos foram suficientes para o controle das fístula em três $(18,75 \%)$, enquanto que no outro $(6,25 \%)$ a esfincterotomia associada ao emprego de prótese biliar foi eficaz apenas até o $4^{\circ}$ mês de pós-operatório quando ocorreu óbito por sepse.

A definição liberal de fístula biliar consiste em extravasamento de contraste durante colangiografia. De outra forma alguns autores consideram fístula somente quando requer cirurgia ou instrumentação das vias biliares, o que explica o número menor complicações ${ }^{12}$. Já Osorio et al. ${ }^{13}$ definem a fístula tardia como sendo aquela de aparecimento no local de inserção do tubo em T após sua remoção.

Os casos de fístula biliar precoce de pequeno débito podem ser controlados deixando-se o dreno aberto ${ }^{4,14}$ ou então praticando-se procedimentos endoscópicos ${ }^{13,15,16,17}$ conforme foi realizado no presente trabalho. Nestas condições as fístulas biliares de pequeno débito são assintomáticas evoluindo para a cura espontânea ${ }^{18}$. O tratamento das fístulas biliares não dependentes da obstrução arterial pode ser prontamente controlado por procedimentos endoscópicos ou percutâneos, ao invés de reoperações ${ }^{13}$. Todavia a maioria dos autores $(51 \%)$ prefere a reoperação e em ordem decrescente: endoscopia, tratamento conservador, drenagem nasobiliar e tratamento percutâneo ${ }^{6}$. Osorio contra-indica, no entanto, a realização de esfincterotomia e advoga a utilização de dreno nasobiliar ou cateter trans-hepático. Sossenheimer et al. ${ }^{19}$ e Lebeau et al. ${ }^{20}$ referem, no entanto, uma incidência de $11 \%$ a $32 \%$ de mortalidade relacionada a reoperações.

Por outro lado, as fístulas de aparecimento tardio, ou seja, após a remoção do tubo em $\mathrm{T}^{13}$ são as que mais preocupam os cirurgiões. Segundo Strata, 70\% das fístulas requerem tratamento cirúrgico, sendo que $94 \%$ das fístulas precoces e $53 \%$ das fístulas tardias necessitam tratamento cirúrgico. A ocorrência desta complicação pode surgir tanto com a remoção precoce ou tardia do dreno de $\mathrm{Kehr}^{4}$. O tipo de material empregado na confecção do dreno em T também deve ser levado em consideração, uma vez que a borracha costuma reduzir o número de complicações biliares relacionadas ao seu emprego ${ }^{21}$. Na presente série de 16 pacientes não se observou fístula biliar após a remoção do tubo em $\mathrm{T}$.
Embora a maioria dos centros transplantadores nos EUA utilize o dreno em $\mathrm{T}^{6}$ a ocorrência de complicações tais como incidência de fístula mais elevada, deslocamento prematuro do mesmo, obstrução, colestase, colangite ${ }^{22}$ fez com que alguns autores propusessem abandonar seu emprego ${ }^{10,23}$.

No grupo 2 (CC) a fístula biliar ao nível da anastomose ocorreu em seis (12\%) dentre os 50 casos. O emprego da CPRE definiu o diagnóstico em quatro casos $(8 \%)$. Entre estes seis pacientes o tratamento expectante foi praticado em dois, colocação de prótese endoscópica em três e laparotomia imediata em um. Exceto em um caso, no qual foi feito tratamento expectante, os demais foram submetidos a reoperações.

Estes dados sugerem uma incidência maior de fístulas quando não se emprega o dreno em T. Por outro lado para alguns haveria o dobro de complicações na anastomose coledococoledociana relativas ao emprego do tubo em $\mathrm{T}^{10}$.

No grupo 2 ocorreram oito casos (16\%) de estenose biliar tardia. Nestes pacientes a CPRE revelou obstrução ao nível da anastomose em todos. Dos cinco (10\%) submetidos ao tratamento mediante a colocação de prótese endoscópica em um (2\%) houve necessidade posterior da realização da anastomose biliodigestiva e em outros dois (4\%) a derivação biliodigestiva foi o tratamento de primeira escolha.

Para os autores que defendem o emprego do tubo em T, a sua utilização facilitaria o processo de cicatrização evitando a ocorrência de estenose tardia. Neste trabalho houve apenas um caso de estenose $(6,25 \%)$ entre os 15 casos onde se empregou o dreno em $\mathrm{T}$, enquanto que nos 72 onde não se empregou o dreno em $\mathrm{T}$ ocorreram oito casos de estenose (16\%), o que está de acordo com a literatura que revelou elevada incidência de estenose quando não se emprega o tubo em $\mathrm{T}^{24,25}$; por outro lado, outros autores $^{22}$ não observaram retrospectivamente diferenças entre as anastomose com e sem o emprego do dreno em $\mathrm{T}$. Nos pacientes do grupo 3 (CDJ) ocorreu apenas um caso de fístula biliar numa reoperação de paciente portador de trombose da artéria hepática. De modo geral, a fístula biliar na anastomose coledocojejunal costuma ser de tratamento mais complexo ao dificultar os procedimentos endoscópicos ${ }^{12}$.

A desvascularização do sistema biliar talvez seja a principal causa das complicações biliares. Além da fístula e da estenose, outra complicação temida é a necrose da via biliar e está diretamente relacionada à trombose da artéria hepática ${ }^{18}$. Em todos os casos a evolução é bastante desfavorável sendo a mortalidade muito alta.

Quanto à lesão de preservação, responsável por estenoses intra-hepáticas múltiplas, dilatações biliares e coleções liquidas, observadas tardiamente (depois de 30 dias), é conseqüente a um tempo de isquemia fria prolongado ${ }^{28,29}$. Embora seja difícil responsabilizar as complicações biliares em função do tempo decorrido desde a retirada do órgão até o implante, na presente série o tempo de isquemia fria foi de 11, 19 horas, o que está de acordo com a recomendação que não se deve ultrapassar 15 horas $^{26}$.

Mecanismos imunológicos caracterizados pela incompatibilidade do sistema ABO explicam a ocorrência 
de $82 \%$ de complicações biliares com doadores incompatíveis no grupo $\mathrm{ABO}$ comparativamente a $6 \%$ nos casos de doadores compatíveis ${ }^{27}$. Nesta casuística os transplantes foram realizados respeitando-se esta compatibilidade.

Complicação descrita como pouco freqüente em $1988^{30}$, a dilatação do ducto biliar não relacionada a zonas de estenose e sim conseqüente à disfunção do esfíncter de $\mathrm{ODDI}^{31}$. Pode ocorrer em $3 \%$ a $7 \%$ dos pacientes e corresponde a $20 \%$ das complicações biliares após o transplante ${ }^{19,20,28,29}$. Pode também ser decorrente de denervação da papila de Vater por ocasião da hepatectomia ${ }^{30} \mathrm{ou}$, ainda, de disfunção preexistente do esfíncter ${ }^{28,29}$. Em nossa série houve apenas um caso desta complicação.

A formação de cálculos ou barro biliar tem sido relatada como conseqüente à presença de estenose biliar e, mais raramente, como decorrente da prótese biliar ${ }^{26}$. Na presente série foram observados três pacientes que evoluíram com calculose tardiamente, todos haviam sido submetidos à anastomose coledococoledociana, sendo que em um foi utilizado o tubo em $\mathrm{T}$ e nos outros dois não. Nos três casos foi indicada a CPRE na tentativa de retirada dos cálculos, no entanto em nenhum dos casos a colangiografia endoscópica com instrumentação da via biliar (utilização de basket) obteve êxito. Foram então submetidos à reoperação com anastomose coledocojejunal em Y de Roux em dois e coledocoduodenal no outro.

Assim, os procedimentos endoscópicos têm permitido o tratamento não cirúrgico destas complicações mediante a colocação de drenos transbiliares por via endoscópica ou pela realização exclusiva da esfincterotomia ${ }^{16}$. Em nossa série a CPRE mostrou-se de grande valor seja quanto ao diagnóstico ou no tratamento das fístulas e estenoses, e deve ser empregada como primeira opção no tratamento das complicações biliares em virtude de seu custo e da sua baixa morbimortalidade quando comparada a reoperações ${ }^{17}$.

A CPRE mostrou-se útil como primeiro procedimento tanto para diagnóstico como apresentando resolutividade em $68,9 \%$ dos casos.

O emprego do procedimento endoscópico tanto nas fístulas como nas estenoses biliares, acompanhadas ou não de calculose biliar, revelou-se útil nesta série, principalmente para controlar estas complicações no pós-operatório imediato permitindo as reoperações mais tardiamente, aguardando-se condições clínicas do paciente mais estáveis. Na presente série ocorreu apenas um óbito por fístula biliar em paciente submetido à anastomose coledocojejunal (grupo CC) no pós-operatório imediato dada a impossibilidade de se realizar manobras endoscópicas por tratar-se de fístula de alto débito. A incidência de complicações biliares foi maior nos grupos CCT 7/16 (43,75\%) e CC 16/50 (32\%) quando comparadas com a anastomose coledocojejunal $1 /$ $12(8,33 \%)$. Embora não haja diferenças estatisticamente significantes quanto à presença de fístulas e estenoses nos grupos CC e CCT, observou-se no presente trabalho incidência mais elevada de estenose tardia da anastomose no grupo CC comparativamente ao grupo CCT.

As complicações biliares observadas no presente estudo, embora sem significância estatística, sugerem que o emprego do tubo em T não se justifica, visto que o seu uso está associado ao risco de complicações que independem da própria anastomose.

\begin{abstract}
Biliary tract complications after orthotopic liver transplantation (OLT) are common and is important to evaluate newer treatment options and compare them to standard surgical treatment. From september 1991 to september 1998, the biliary tract reconstruction was analysed in 78 OLT. Choledochocholedochostomy employing a T-tube (CCT) was performed in 16 patients (20.5\%), choledochocholedochostomy without the T-tube (CC) in 50 $(64.1 \%)$ and choledochojejunostomy (RYCJ) in $12(15.4 \%)$. We observed $24(31,2 \%)$ biliary complications, 12 of them within the first month. There were 12/78 (15,6\%) fistulas $(C C T=5, C C=6, R Y C J=1) 9 / 78(11,7 \%)$ strictures $(C C T=1, C C=8)$ and $3 / 78(3,9 \%)$ calculosis $(C C T=1, C C=2)$. Retrograde cholangiopancreatography endoscopy (ERCP) was employed in 19/78 patients (24,7\%) with improvement in 13 (61,9\%). ERCP was employed in 11 cases of biliary fistula leading to improvement in $4 / 5$ patients in group CCT and 5/6 patients in group CC. On the other hand, from the 8 cases of biliary stricture submitted to endoscopic procedure, obstructive syndrome were successfully managed in 4/8 patients in group CC. Choledochocholedochostomy employing a T-tube was successfully in 7/16 cases (43,75\%) and choledochocholedochostomy without T tube in 16/50 cases (32\%.). Only 9 out of 24 biliary tract complications required reoperations $(C C T=1, C C=8)$. There were 5 cases of hepatic artery thrombosis (HAT) among 78 patients. Median follow-up after the treatment of biliary tract complications was 14 months ranging from 1 to 6,8 years. In this series, $8 / 78(10,4 \%)$ patients died (5, HAT, 1 CCT, 2 CC). The overal incidence of biliary complications was higher in groups CCT(7/16), CC (16/50) when compared to RYCJ (no complication observed). There was no significant difference related to the presence of fistula or stricture between CCT and CC groups. The incidence of early and late complications was similar in both groups (CCT and CC). These results suggest that biliary leakage and stricture rates are not significantly affected by the use of the T-tube. ERCP applied to selected cases provided an acurated diagnosis and treatment, being a reliable procedure as a first choice to improve the treatment. It has proved to be safe and effective, avoiding the need of a more invasive surgery, which should be considered for nonresponsive patients.
\end{abstract}

Key words: Liver; Transplantation; Biliary complication. 


\section{REFERÊNCIAS}

1. Klein AS, Savador S, Burdick JF et al. Reduction of Morbidity and Mortality from Biliary Complications after transplantation. Hepatology 1991; 14: 818-823.

2. Lerut J, Gordon RD, Iwatsuki S et al. Biliary Tract Complication in Human Orthotopic Liver Transplantation. Transplantation 1987; 43: 47-51.

3. Greif R, Bronsther OL, Van Thiel DH et al. The incidence, timing, and management of biliary tract complication after orthotopic liver transplantation. Ann Surg 1994; 219: 40-45.

4. Shuhart MC, Kowdley KV, McVicar JP et al. Predictors of Bile Leaks after T Tube Removal in Orthotopic Liver Transplant Recipients. Liver Transpl Surg 1998; 4: 62-70.

5. Rossi AF, Grosso C, Zanasi G et al. Long-Term Efficacy of Endocopic Stenting in Patients with Stricture of the Biliary Anastomosis after Orthotopic Liver Traansplantation. Endoscopy 1998; 30: 360-366.

6. Vallera RA, Cotton PB, Clavien PA. Biliary Reconstruction for Liver Transplantation and Management of Biliary Complication: Overview and Surveys of Current Practices in the United States. Liver Transpl Surg 1995; 3 : 143-152.

7. Wall WJ, Grant DR, Duff JH et al. Liver transplantation without venovenous bypass. Transplantation 1987;43: 56-61.

8. Tzakis A, Todo S, Starzl TE. Orthotopic Liver Transplantation with preservation of the inferior vena cava. Ann Surg 1989; 210: 649-655.

9. Starzl TE, Putnan CW, Hansbrough JF et al. Biliary compliactions after liver transplantation with special reference to the biliary cast sindrome and techniques of secondary duct repair. Surgery 1977; 81:212-221.

10. Rouch DA, Edmond JC et al. Choledochocholedochostomy without a T-tube or internal stent in transplantation of the Liver. Surg Gynecol obstet 1990; 170: 239244.

11. Wilson BJ, Marsh JW, Makowka M et al. Biliary Tract Complication in Adult Orthotopic Liver Transplantation. Am J Surg 1989; 158: 68-70.

12. Lopez RR, Benner KG, Ivancev $\mathrm{K}$ et al. Management of Biliary Complications After Liver Transplantation. Am J Surg 1992; 163: 519-523.

13. Osorio RW, Freise CE, Stock PG et al. Nonoperative Management of Biliary Leaks after Orthotopic Liver Transplantation. Transplantation 1993; 55: 10741077

14. Nuño J, Vicente E, Turrión VS et al. Biliary Tract Reconstruction After Liver Transplantation: With or Without T-Tube? Transplant Proc 1997; 29: 564-565.

15. Strata RJ, Wood P, Langnas NA. Diagnosis and treatment of biliary tract complication after orthotopic liver transplantation. Surgery 1989; 106:675-684.

16. Wolfsen H, Porayko MK, Hughes RH et al. Role of endoscopic retrograde cholangiopancreatography after orthotopic liver transplantation. Am J Gastroenterol 1992; 87: 955-960.

17. O'Connor HJ, Vickers CR, Buckels JAC et al. Role of endoscopic retrograde cholangiography after orthotopic liver transplantation. Gut 1991; 32: 419-423.

18. Zajko AB, Campbell WL, Longsdon GA et al. Biliary complications in liver allografts after hepatic artery oc- clusion: a 61/2 year study. Transplant Proc 1988; 20 (suppl 1): 607-609.

19. Sossenheimer M, Slivka A, Carr-Locke D. Management of extrahepatic biliary disease after orthotopic liver transplantation: Review of the literature and results of a multicenter survey. Endoscopy 1996; 28: 565571.

20. Lebeau G, Yanaga K, Marsh JW. Analysis of surgical complication after 397 hepatic transplantations. Surg Gynecol Obstet 1990; 170: 317-322.

21. Neuhaus P, Blumhardt G, Bechstein WO et al. Technique and results of biliary reconstruction using side-to-side choledochocholedochostomy in 300 orthotopic liver transplants. Ann Surg 1994; 219: 426-434.

22. Rolles K, Dawson K, Novell R et al. Biliary anastomosis after liver transplantation does not benefit from $\mathrm{T}$ tube splintage. Transplantation 1994; 57:402-404.

23. Friend PJ. Overview: Biliary Reconstruction after Liver Transplantation. Liver Transpl Surg 1995; 1: 153-155.

24. Vougas V, Rela M, Gane E et al. A prospective randomized trial of bile duct reconstruction at the liver transplantation: T-tube or not T-tube? Transpl Int 1996; 9: 392395.

25. Alvardo AA, Moreno-Gonzalez E, Gomez SR et al. Biliary stenosis in patients treated with liver transplantation: Diagnostic approach. Amali Ital 1995; 66: 711718.

26. Sanchez-Urdazpal L, Gores GJ, Ward EM et al. Ischemictype biliary complications after orthotopic liver transplantation. Hepatology 1992; 16: 49-53

27. Sanchez-Urdazpal L, Batts KP, Gores GJ et al. Increased bile duct complications in liver transplantation across the ABO barrier. Ann Surg 1993; 218: 152-158.

28. Clavien PA, Camargo CA, Baille J. Sphincter of ODDI dysfunction after liver transplantation. Hepatology 1982; 2: 614

29. Clavien PA, Harvey PRC, Strasberg SM. Preservation and reperfusion injuries in liver allografts: Overview and synthesis of current studies. Transplantation 1992; 53: 957-978.

30. Stieber AC, Ambrosino G, Kahn D et al. Unusual complication of choledochocholedochostomy in orthotopic liver transplantation. Transpl Proc 1988; 20: 619 620.

31. Douzdjian V, Abecassis MM, Johlin FC. Sphincter od ODDI dysfunction following liver transplantation: screening by bedside manometry and definitive manometry evaluation. Dig Dis Sci 1994; 39: 253-256.

\section{ENDEREÇO PARA CORRESPONDÊNCIA}

Dr. Luiz Sérgio Leonardi

Rua Coronel Quirino 1.299/12 andar

13025-000 - Cambuí - Campinas-SP 